PUPIL: International Journal of Teaching, Education and Learning

ISSN 2457-0648

Teodora Mabulay Salubayba, 2022

Volume 5 Issue 3, pp. 238- 253

Received: 13 $3^{\text {th }}$ September, 2021

Revised: 09th November 2021, 24 th January 2022

Accepted: 21st February 2022

Date of Publication: 22 ${ }^{\text {nd }}$ February, 2022

DOI-https://doi.org/10.20319/pijtel.2022.53.238253

This paper can be cited as: Salubayba, T. M. (2022). Lived Experience of Full-Time Teachers' Graduate Schooling During A Pandemic. PUPIL: International Journal of Teaching, Education and Learning, 5(3), 238-253.

This work is licensed under the Creative Commons Attribution NonCommercial 4.0 International License. To view a copy of this license, visit $h$ ttp://creativecommons.org/licenses/by-nc/4.0/ or send a letter to Creative Commons, PO Box 1866, Mountain View, CA 94042, USA.

\title{
LIVED EXPERIENCE OF FULL-TIME TEACHERS' GRADUATE SCHOOLING DURING A PANDEMIC
}

\author{
Teodora Mabulay Salubayba,
}

PhD, Assistant Professor, Educational Research and Evaluation, College of Education, University of the Philippines Diliman, Quezon City, Philippines

tmsalubayba@up.edu.ph

adorysalubayba@gmail.com

\begin{abstract}
This study portrays the unique experiences of graduate students in education during the pandemic and the commonalities of the interpretations and essences of those lived experiences. In the Philippines, some graduate students managed to survive in their full-time teaching and graduate education that was entirely remote online classes, where everything was home-based during the pandemic. Sixty-eight full-time teachers enrolled in the different graduate degree programs in education in one of the prestigious universities in the Philippines volunteered to share their stories via emails and informal audio-video chat. Commonalities among the unique and multiple realities of the experiences portray the essence of pandemic phenomenon like balance and equanimity for survival when everything was home-based, the importance of holding on to the lived values and personal traits as a stronghold, fortress, and strong weapon during the crisis, and a clear focus on finishing a graduate degree amidst pressing duties and responsibilities in full-time teaching, in the family, and graduate schooling. Findings suggest further inquiry on the graduate students' lived experiences during a pandemic across cultures
\end{abstract}


in various colleges and universities to uphold full-time teaching and graduate schooling toward efficient school leadership and governance during difficult times.

\section{Keywords}

Pandemic Phenomenon, Graduate Students, Full-Time Teaching, Lived Experience

\section{Introduction}

The COVID-19 global pandemic created a wide array of disturbing, painful, and intricate experiences among people from different walks of life. The unique and multiple experiences were felt as reports and empirical studies swarmed on the internet that revealed the eagerness of people to share their views and beliefs regarding the pandemic. Short- and longterm solutions were offered so as not to exacerbate its effects and impacts on physical health, mental, and psychological. The education sector was one whose main concern was the sustainability of quality education despite the looming negative impact on instruction, the basic and higher education learners who may be not learning at all as expected. Graduate students in education who were full-time teachers and attending graduate schools were in the best capacity to portray the reality of teaching and learning during the pandemic. The actual experiences of these teachers provided meaning on the struggles and survival when seemingly nothing can be held on to but the strengths and values acquired and lived through, yet not brought into consciousness before the pandemic. Challenges like the pressing family concerns and responsibilities, financial constraints, and work-related concerns were some of the challenges the graduate students had experienced even before but were more intense during a pandemic. Setting priorities judiciously was reinforced as the demanding and conflicting tasks and responsibilities piled up. Dropping from the graduate program or delaying graduation were among the coping strategies considered. The gravity of struggles was more pronounced during the pandemic despite the various forms of university's financial assistance, adjusting course works, and redesigning programs to cater to the needs of both the students and the professors. University personnel and faculty members' initiatives, students-led consultation alleviated if not addressed the nagging concerns, problems, and issues of graduate schooling as the pandemic jeopardized formal schooling for almost two academic years.

\section{Literature Review}

Educational researches are shared and published worldwide at the time of the pandemic. Educational crises worldwide affect a large percentage of learners during the pandemic (Covid19 and Education, 2020; United Nations, 2020a). The impact is felt on teaching, learning, on 
students' emotional and psychological experiences including higher education (Schleicher, 2020; Pokhrell \& Chhetri, 2021; UNESCO IESALC, 2020, Kee, 2021, Simbulan, 2020). Some issues matter among students and teachers such as the importance of instructional technology on pedagogy and educational activities and e-learning, online learning in a time of the COVID19 pandemic (Tria, 2020; Adedoyin \& Soykan, 2020; Marqueza et al., 2020; Beane, 2020; Gantner \& Campbell, 2020; Dhawan, 2020; Mulyani et al., 2021).

A few studies looked into the experiences of graduate students in education who are full-time remote online teachers. Graduate students being both students and instructors experience disappointments, anxiety, fear, falling short of power and control, adopting virtual instruction, the coping strategies and seeking relief (Kee, 2021), navigating a new educational environment, and the struggles and experiences harming their mental health (Zahneis \& Williams, 2020).

Exploring the experiences of the graduate students through in-depth informal sharing of stories would gain insights and a deeper understanding of the reality of teaching and learning during the pandemic. The scenario could spur experts and specialists to revisit graduate education curricular programs, particularly the assessment, evaluation process, and procedures. The lived experiences of the graduate students are a timely topic for phenomenological inquiry during the pandemic. Investigation regarding various reactions and perceptions to the phenomenon as experienced and lived through is what the phenomenological study undertakes (Fraenkel \& Wallen, 2008). Reflectively attentive to how human beings lived through the experiences in the immediate present recovered in the elusive past is a phenomenological attitude (Patton, 2015). Patton further mentioned that the nature and intensity of the experience like being struck by lingering discomfort somehow seen beyond words as one tries to appropriate retrospectively the experience. Graduate students experienced difficulties and limitations in graduate online learning because of pressing and conflicting tasks and responsibilities in the family and full-time teaching, which made it even more difficult with unstable internet connections which the whole household depended on to survive online learning (Salubayba, 2021). Salubayba further reported that the students were able to cope with the travails the pandemic brought because of the support and assistance of the course professor, immediate relatives, and friends. Coping strategies included making choices, managing daily activities, and self-determination to earn a graduate degree. Self-determination theory claimed that managing one own's life is important to psychological health (Cherry, 2021). The strong desire to gain fulfillment and grow in the situation is a usual driving force among people (Ryan \& Deci, 2020). The limitations, struggles, coping and survival embedded in the experiences 
led the graduate students to the awareness of how they shifted and adjusted their paradigms that shaped the reality and formed deeper meaning on the lived experiences.

\section{Methods and Procedures}

This qualitative study used phenomenological inquiry that focused on the lived experiences of graduate students in education. Questions like "How are you doing since the onset of the pandemic? What it is like to do full-time teaching at home during a pandemic? What it is like attending graduate schooling during a pandemic? How would you describe the reality of this pandemic experience?" guided the online informal and in-depth interview and sharing of journals online. The study made use of qualitative in-depth online interviews sharing of personal journals, and qualitative analysis of the data collected in a natural setting. The qualitative interview in contrast to the use of standardized and structured questions is based on the topics to be discussed (Babbie, 2001); in this study the pandemic phenomenon experience. Babbie stated also that qualitative data analysis aims to discover underlying meanings and patterns of relationship; in this study the commonalities of the descriptions, perceptions, and interpretations of the phenomenon. Sixty-eight full-time teachers pursuing a graduate degree in education volunteered to share their lived experiences during the pandemic. Informal individual interviews via messenger video and audio chat and zoom meetings illuminated spoken and unspoken words, and the feelings they expressed that contributed to the deeper understanding of the experiences. The participants consisted of 22 married, and 46 single or unmarried. Out of the 46 unmarrieds were four sole breadwinners and providers of their families. The composition of the participants was not used to compare responses and quotes but provided contexts for meaningful interpretations of the lived experiences. Memberchecking clarified and validated with the participants the transcribed responses on the online in-depth interviews and informal journals that were shared online. Ethical considerations were strictly observed that included respect for the opinions and shared stories of the students, concealed identities, anonymity, data privacy, and confidentiality. Theoretical sampling was applied as more data collected further refined themes. (Corbin \& Strauss, 2008; Birks \& Mills, 2015; Denzin \& Lincoln, 201). Phenomenology assumed the essence or essences present to shared experiences (Patton, 2015). Commonalities discovered on the perceptions and reactions to the lived experiences were identified. These were regarded as the essential characteristics of the pandemic phenomenon as the graduate students have experienced. The data were discarded once they were analyzed, and the essence of the phenomenon was already identified. 


\section{Results and Findings}

Graduate students' lived experiences portrayed the phenomenon of full-time teaching and graduate schooling during a pandemic. The students' descriptions and perceptions of the pandemic experience and the meanings they attached to the experiences helped to identify the common and essential characteristics of the phenomenon. The intricate, overlapping, and at times conflicting demands of the various tasks and responsibilities while confined at home brought into consciousness the realities of the phenomenon that they considered extraordinary ordeals that led them to readjust and shift their life's paradigm. Teaching and learning during a pandemic besides entirely online were doubly stressful and the physical, mental, and psychological fatigue were beyond measure as the students reflected on. Various organizations that provided support and assistance for mental health during the pandemic were not enough as the graduate students realized that reflecting on the experiences, they can draw strengths from within, the lived personal traits and values they were not so fully aware of before. Appreciative of their characteristics and strengths, they were able to manage and loosen the knots of pressing and urgent tasks and responsibilities at home, in full-time teaching, and in graduate schooling. They were able to conquer and embrace the realities that were considered impossible because of the anxieties, uncertainties, and seemingly indefinite and infinite trials and difficulties. Commonalities discovered and identified on the multiple realities of the experiences consisted of the following: The pandemic phenomenon was the test for balance, equanimity, and setting priorities judiciously amidst the hurdles and travails that pervaded the lives of the people. It was a time for evaluating, readjusting, and shifting life's paradigm while maintaining a clear focus on the desired graduate degree. Last, the pandemic was the time to hold on to the lived personal traits and values acquired across the years of teaching and attending graduate school. The context of being married, as fathers and mothers tending to their children while trying to uphold quality full-time works as teachers, as single or unmarried but family breadwinners, provide a deeper understanding of the multiple realities of the experiences. The world of the graduate students revolved around their family, full-time teaching, and graduate schooling where the spectrum of expectations and demands on the mounts and piles of various tasks and responsibilities were all contained at home. What they considered an extraordinary and unusual world became so ordinary and usual as they learned to trudge so naturally on the pandemic phenomenon. 


\subsection{The Reality of Graduate Students' Teaching, Learning and Preserving the Family During A Pandemic}

Multi-tasking became imperative during the pandemic. The participants described their everyday living as tough and oftentimes exhausting. The need to stretch and flex the daily schedules was evident. Time was considered so precious, as the wall clock was the centrepiece of the house. Full-time teaching, graduate schooling, doing household chores, attending to family members, doing errands for the family, were part of the daily routine. Parents were monitoring and assisting their children's online classes, doing all the household chores as hiring household helpers was restricted during the COVID-19 pandemic. Being full-time teachers and at the same time full-time parents attending to family concerns especially the online schooling of children and doing graduate school requirements were considered a test of flexibility, composure, and maintaining sanity when faced with compelling, conflicting, and demanding tasks and responsibilities. The unmarried participants' experiences were almost similar, staying with the family, attending to household chores as well, assisting the siblings' online learning, contributing to the family's financial needs, and running errands for the entire family. Four out of the unmarried participants were breadwinners and sole providers, caring and attending to younger siblings and their elderly senior citizen parents. Financial constraints were evident during the pandemic as unemployment heightened but the participants were grateful for the full-time teaching that made them survive and managed the family's financial needs. Graduate students struggled amidst compelling tasks and priorities in the family, work, and graduate schooling. The realities of the pandemic experience were vivid as reflected in the following sampled quotes from the informal online interview and personal journals shared online.

Our brains are not wired for this kind of set-up, our bodies are not energized to do all school tasks at home, the demands from teaching work strained my schedule, I always look at my watch (Student JC).

There has been no clear delineation between day and night, weekdays from weekends, holidays from workdays as everything done at home, preparing lessons, checking students' papers, checking on my children, preparing meals for the family, everybody in the house so conscious of time (Student MTA).

One of the hardest semesters, not because of the subjects enrolled, but because of the situation we have, the house was the only place where everything was done, everybody moved around doing tasks, we all got stacked (Student NYAB). 
The pandemic has worsened my anxiety as a mother/homemaker and my teaching profession, slowed down my progress in my professional development, concerns about my family continually disturbed my focus on work, looking at my watch, how much time left to accomplish everything at home (Student $\mathrm{PJ})$.

We all struggle to survive the entirely online remote learning and working from home, my children, my husband, sharing the internet connection at home, my children working on the shared laptops and the available gadgets. (Student BM).

We are preoccupied navigating the new normal education, unfamiliar virtual classroom, things are hassles, sometimes resulted to petty quarrels at home, the siblings demanding for stable internet connection (Student AIES).

Since confined at home, I became close to the friends of my children as they communicated online. I became familiar and at ease with our neighborhood through limited interaction. There is a feeling of familiarity and belongingness where I live as people with limited movement confined in one place, we all experience the difficulties and limitations (Student JJ).

The descriptions of what the world was after more than a year of experiencing the pandemic brought to light a clear picture of what had become the participants as full-time teachers, graduate students, and keepers of the family. The way they considered themselves active or even significant members of the family was interpreted as the family keepers, keeping and preserving the family's sanity and psychological well-being in the best shape, besides providing financial and material assistance. Commonalities were identified among the stories of the participants that lend insights on the themes related to balancing priorities, adjusting life's paradigm, and personal traits and values that brought into the consciousness, cherished and lived through.

\subsection{Test for Balance, Equanimity, and Setting Priorities Judiciously}

The participants perceived the pandemic experience as weakening, and depleting energies. However, as they described and found meaning in the experiences, one could say that no matter how fazing and disheartening the experiences, there will always be a tinge and grain of hope and light. The significant lessons life has to offer were found during the trying times. The pandemic phenomenon has tested the participants' capacity to balance and maintain equanimity when all the tasks and responsibilities were urgent and compelling. Setting priorities was a quandary when anything, every task, and responsibility appeared crucial and critical. Reflective decisions helped to arrive at a compromise and eased the tensions and stress of each day. This essential characteristic of the experience was revealed in the sampled quotes. 
Caught in a never-ending dilemma, but taking one day at a time, I remained calm and relaxed, for everything can be done, just rank my priorities, what was urgent, what can be set aside for a while, or sacrifice for a while (Student ROB).

I have to keep cool, else I will miss out on important things, I was so nervous and tense the first months of the pandemic, so anxious to attend to all tasks, I learned the craft then, cool else I will collapse (Student ASDN).

Being an online learner requires more time and discipline to compartmentalize my many roles, just need to prioritize and accept my limited capacity (Student AD).

At the onset of online learning, I got mixed up where everything was accomplished and done at home, my little son constantly wanted to play and talk to me, he was used to a set-up that when I'm home, it is play and storytimes. I usually work when he was already asleep. Now, it is different, I have to work while he is awake. I was able to balance the usual home tasks and online teaching from home and graduate school requirements lying on my desk (Student $\mathrm{RBJ})$.

Online learning requires a designated space at home for uninterrupted communication with my students as a teacher, and my teacher in the University as a student, where I can accomplish the tasks and can say to myself, I was able to manage them (Student NGRD).

Concerned about doing best both in teaching and graduate studies, attending religiously to duties and responsibilities in the family was evident among the participants. The atmosphere of equanimity in the house or the home had eased the difficulties and limitations during the COVID-19 pandemic online teaching and learning and made possible the welfare of the entire family. The family was the top priority of the participants, while full-time teaching work was their utmost concern as a source of income for the family. Graduate schooling was sacrificed as the last priority. However, the participants expressed that they will never abandon or give up the desire and determination to earn a graduate degree. The line-up of conflicting priorities led to the judicious decision of family first and work on a parallel frame. Highlighting the essentials during the pandemic and setting aside other priorities was the consequence of the reflective evaluation of one's paradigm in life. While aiming for the graduate degree was put aside, it was still considered part of family welfare not just for personal gain. Everything was for family, the work, the achievements, the shifting and readjusting priorities. 


\subsection{Evaluating, Readjusting, and Shifting Life's Paradigm While Maintaining a Clear Focus on the Graduate Degree}

The pandemic experience lent insights on what to focus on, what to adjust, and how to organize and deal systematically with some unexpected events and occurrences besides the daily routine. It was considered the best time for evaluating, adjusting readjusting, and shifting life's paradigm while maintaining a clear focus on the desired graduate degree. In the earlier survey conducted during the first semester of the graduate schooling, reports revealed the advantages and disadvantages, benefits and setbacks of attending synchronous and asynchronous online classes, doing the course requirements, and meeting deadlines (Salubayba, 2021). More than a year of struggles and survival, coping with the difficulties and limitations, reflecting on the experiences, the intensity of discomfort was felt in words and beyond spoken words. The weight of the tasks and responsibilities, the home-based full-time teaching and schooling, and the house that turned into both school and office where all the members of the family interact was an accepted reality, a natural and normal setting. Adjustment and readjustment were no longer a struggle but a spontaneous coping mechanism. This influenced how the graduate students shifted the paradigm, that life is a continuous process of evaluation, assessment, and adjustment. The focus remained but adjusted and readjusted to cater to the needs of the whole family. Whatever the accomplishments whether on work or schooling, were all for the family. The participants expressed that everybody in their family learned to adjust and adapt to the new setup. The inevitable changes and adjustments influenced their outlook, beliefs, and views regarding teaching, learning, and the family. These descriptions and insights were reflected in the sampled quotes.

My tendency to do the best in everything and for everyone in my life needs to be downplayed. I realized I cannot do everything like I used to, what is important, I focus on the needs and concerns of the family (Student JAP).

Becoming a successful professional in a prestigious university was very important to me. I stick to my goal to finish the degree, no matter what road I must take, I just have to attend to pressing duties at home and in teaching (Student MAD).

My perseverance and endurance were tested, I learned to accept the realities of life and move forward. I adjusted my goals and aspirations for my study. I am forced to adjust to the new situation (Student JBTS).

With a clear goal in mind, to achieve the learning goals, I embraced the technical side of conducting online classes, attending online classes, presenting myself virtually, entirely shifting to online mode became spontaneous (Student LP). 
If I going to draw the picture of my life, family first, teaching next, last graduate schooling, I adjusted to parallel positioning to check and counter-check at least accomplishing a little not zero (Student CC)

As a teacher, I should be ready to learn, unlearn, and relearn, to upgrade ourselves to meet the needs of our learners (Student FRD).

The pandemic strengthened my resolve to finish my doctorate, I learned to adjust

to this setup in the family, the reality we all need to accept, these how things are (Student LS).

Looking at the shared reality of the pandemic experience, home-based teaching and learning were considered the responsibility of the whole family. Becoming effective teachers and learners in whatever subjects and courses, the shared responsibility and accomplishments whether great or small were considered occasions to celebrate and reflect upon. The participants mentioned that nothing is so impossible when strongly resolved. Determination to pursue and earn a graduate degree be it masters or doctoral redound to career advancement and professional growth not only for personal gain but for the welfare of the family. With strong self-determination to succeed in whatever endeavor, a person can manage one own's life which is very important to psychological health (Cherry, 2021). Ryan and Deci (2020) assumed that people are usually driven by a need to improve and grow in whatever situation they are in. The graduate students expressed that their focus on learning influenced their children and siblings as well, thus determination for self-directed learning pervaded the family atmosphere during the pandemic. The family members became conscious and aware of the preoccupations of each one. The family cohesiveness was nurtured and encouraged a positive outlook despite the difficulties and trying experiences.

\subsection{Holding on to Lived Personal Traits and Values}

The pandemic was not entirely different from other phenomena that brought pain and desolation. The manner the graduate students described, handled, and interpreted the unique and multiple experiences lent insights to the common and essential characteristics of the pandemic like the traits and values that made all things possible as they experienced and lived through it. The difficulties encountered were turned into positive realizations, discovering personal traits and values acquired across the years of teaching and learning. Reflecting on the experiences was considered crucial for reckoning, the time to figure out what was urgent and essential. The pandemic encouraged retrospection on what they went through, who they are as a person, their strengths, traits, and values that became their stronghold and fortress to embrace and conquer the situations. The lived personal traits included being devoted and loyal to family 
and full-time teaching, honest and sincere in dealing with relatives, colleagues, and friends, being religious and spiritual, faithful to prayer life and daily reflections. Their values consisted of empathy, understanding, honesty, courage, achievement, and success. The participants overcame the hurdles of the pandemic and were appreciative of the little accomplishments and building a closer relationship with the entire family. These were not given much attention before the pandemic as their preoccupations before were material provision for the family and self-gratification. The following were samples of direct quotes that supported the essential characteristic of the pandemic related to discovering personal traits and values

Amid challenging situations, it is important to set aside time to reflect and a few moments for prayer, inviting the family, my husband, and children to join me, I have been a religious person, and being one made me hang on (Student RRM). Online learning challenged my ability to stay on and to concentrate, and strong spiritual connection to thrive in this situation_(Student LC).

I realized I have been so devoted to my family, my top priority. But I worry so much about my teaching as well, my students ... my loyalty to my family and work across my years of being a teacher had grown stronger (Student IET).

I appreciated my capacity and strength to surpass the situation. It was impossible at first, but thinking of the family, there is that strong desire in me to transcend, thinking that everybody is in this situation. I cannot help but think of other people as well, not only my family (KCP).

I value quality time for my children, to help them achieve success in their studies, as I tried to gain achievement and success for my graduate studies as well (Student JAG).

I have been doing well enough, coping in this COVID-19 pandemic, so appreciative even in my small accomplishments, appreciative of my family, my children, the people who were kind enough to help (Student SMC).

I have all this understanding and patience, I am observant of the people around me, I became conscious of how others feel about this situation, I am living in the present moment most of the time, feeling, sensing, reflecting, on this pandemic in the long run helped although painful (Student DN).

It was evident among the participants the loyalty and determination to sustain quality full-time teaching and a strong focus in graduate schooling for the welfare of the family despite the looming uncertainties as to when the pandemic would end. It was an accepted reality that the pandemic phenomenon brought qualms, trepidations, and anxieties, no matter what and 
where people are. The personal traits and values remained the source of strengths and energy for survival and keeping the family intact. The pandemic made them think of how strong their traits and values were and discovered that there were more positives than negatives after all. Things were not easy, but the participants value time to think, reflect, decide, and act right.

\section{Conclusion and Discussion}

The graduate students' unique experiences of the COVID-19 pandemic phenomenon depicted the reality of online teaching and learning that were all confined at home. This resulted in confused delineation between tasks in the house and those work- and school-related. The unique and multiple experiences lent insights to the essential characteristics and structure of the phenomenon that included the test for balance, equanimity, and setting priorities judiciously amidst the hurdles and travails the pandemic brought to the life of the people. Further, there was the essence of evaluating, adjusting, and readjusting life's paradigm, and shifting focus on the necessities and most urgent to cope with the trying situation, while maintaining a strong desire to earn a graduate degree. Holding on to the lived personal traits and values acquired across the years of teaching and attending graduate school were realized as the stronghold and fortress; the priceless treasure gained across the years of teaching and learning. The contexts of being parents attending to their children's concerns, trying to sustain quality full-time works as teachers, as single or unmarried but family breadwinners, and attending to both teaching and graduate schooling, resulted in a deeper understanding of the pandemic multiple realities. Delving and reflecting on the shared experiences was the discovery of the apparent commonalities concerning perceptions and interpretations of the pandemic phenomenon.

The lived experiences of the graduate students mirror a real and clear picture of struggles and survival in full-time teaching and learning during the pandemic. They gained a deeper understanding of their daily experiences that resulted in the acceptance of reality. The bulk and sometimes burden of responsibilities were brought into consciousness, but the traits and values were the sources of strength to carry on. The weight of the pandemic was felt deeply on full-time teaching, online learning, and household chores that were confined in the house where all the family members relate and interact every day. Hampered with the pressing work and studies, the various concerns and responsibilities, and threats to personal and family health across months during the pandemic were part and parcel of the struggles. The graduate students learned that adjustment and readjustment on schedules and priorities were just part of daily survival. They considered the pandemic phenomenon as an unusual and distinct family 
experience when teaching and learning were all home-based. Overlapping, compelling, and oftentimes conflicting daily tasks became more intricate with their children and other family members demanding attention, assistance, and time, while full-time online teaching requires more technical and computer skills. The goal to pursue and earn a graduate degree was considered the secondary priority, while the family and work were the primary concern.

Graduate students' roles and range of responsibilities grew and felt deeply in the ordeals during a pandemic like teaching and attending to the needs of the undergraduates, working on collaborative and individual faculty research, and dealing with their own families' concerns and needs (Smith \& Ogilvie, as mentioned in Zahneis \& Williams, 2020). The challenging experiences of teachers and students, and the entire education sector as they transition to entirely remote learning during the pandemic produced a wide spectrum of concerns and realizations such as the alternative but effective learning pathways to guarantee access to quality education, (Kee, 2021; Marqueza et al, 2020; Pokhrell \& Chhetri, 2021; Schleicher, 2020; Tria, 2020; Covid-19 and Education, 2020), the importance of instructor personality, and student-focused instruction (Waldeck et al, 2020; Norell, 2020).

The participants became reflectively attentive to the various forms of difficulties and limitations they went through that were felt beyond spoken words. The feeling of discomfort, pain, and distress had changed into opportunities for self-reflection. The fruit of which includes the strong determination to earn a graduate degree, become effective and dynamic teachers, to accomplish something good for the entire family. Every accomplishment whether small or great was considered for a family affair not just for personal gain. In retrospect, the pandemic experiences in more than a year of confinement at home, made them grow not only in age but psychologically and spiritually. These captured the reality of shifting paradigms that help bridge any gap in online teaching and learning. These were expressed as a strong commitment to the teaching profession and lifelong learning, setting priorities, and balancing to achieve the best for the family, work, and graduate studies. Multi-tasking, ingenuity, and foresight alleviate the weight of trepidations and difficulties.

Future research might address the limitations of this study by considering the experiences of graduate schooling in other disciplines not only in the field of education. Crosscase and multiple-case analysis of the graduate schooling experiences during health-related crises in different colleges and universities would add to the existing pool of useful information for graduate program evaluation and assessments, curricular planning, and policy-making. Factors like socioeconomic, school culture and environment, the national and immediate 
community support, might create a different or similar picture of the lived experiences of the graduate students during the pandemic.

\section{REFERENCES}

Adedoyin, O. B., \& Soykan, E. (2020). Covid-19 pandemic and online learning: The challenges and opportunities. https://doi.org/10.1080/10494820.2020.1813180

Babbie, E. (2001). The Practice of Social Research (9th ed.) USA: Wadsworth.

Beane, R. (2020). Engaging the Snapchat Generation. The best of the 2020 Teaching Professor Conference. Retrieved from https://www.magnapubs.com/wpcontent/uploads/2021/02/Best-of-TPC-2020.pdf

Birks, M., \& Mills, J. (2015). Grounded Theory: A Practical Guide (2nd ed.). SAGE Publications, Inc.

Cherry, K. (2021)._Self-determination theory and motivation. Retrieved from https://www.verywellmind.com/what-is-self-determination-theory-2795387

Corbin, J., \& Strauss, A. (2008). Basics of Qualitative Research: Techniques and Procedures for Developing Grounded Theory. SAGE Publications, Inc.

COVID-19 and Education: How Education Unions are Responding (A Survey Report) 2020). Brussels: Education International. https://issuu.com/educationinternational/docs/2020_covid19_survey_report_eng_final

Denzin, N., \& Lincoln, Y. (2013). Collecting and Interpreting Qualitative Materials (4th ed.).

SAGE Publications, Inc.

Dhawan, S. (2020). Online Learning: A Panacea in the Time of COVID-19 Crisis. Journal of Educational Technology, 49(1) 5-22.https://doi.org/10.1177/0047239520934018

Fraenkel, J. R., \& Wallen, N. E. (2008). How to Design and Evaluate Research in Education. McGraw-Hill Co. Inc.

Gantner, M. W., \& Campbell, M. (2020). Bridging Technology and Pedagogy with an Online Teaching Faculty Toolkit, The best of the 2020 Teaching Professor Conference.

Retrieved from https://www.magnapubs.com/wp-content/uploads/2021/02/Best-ofTPC-2020.pdf

Kee, C. E. (2021). The impact of COVID-19: Graduate students' emotional and psychological experiences, Journal of Human Behavior in the Social Environment. https://doi.org/10.1080/10911359.2020.1855285 
M. Salubayba, T. (2021). Pandemic Online Learning Experiences of Graduate Students in Education: Motivations, Hurdles, and Coping Strategies. International Journal of Global community, 4(3 - Nov), 199 - 216. Retrieved from https://journal.riksawan.com/index.php/IJGC-RI/article/view/95.

Marqueza, L. P., Olivar, M. V. V., Brijuega, C. E., Ombao, R. P., Cerio, W. C., \& Baes, F. D. (2020). Education and COVID-19: Experiences and insights from a developing country. Access: Contemporary Issues in Education, 40(1), 84-90. https://doi.org/10.46786/ac20.5188

Mulyani, Fidyati, Suryani, Suri, M., \& Halimatussakdiah. (2021). University students' perceptions through e-learning implementation during COVID-19 Pandemic: Positive or negative features dominate? Studies in English Language and Education, 8(1), 197 211.

Norell, L. (2020). Stop Blaming Students! Why We Must Teach Students, Not Content, The best of the 2020 Teaching Professor Conference. Retrieved from https://www.magnapubs.com/wp-content/uploads/2021/02/Best-of-TPC-2020.pdf

Patton, M. Q. (2015). Qualitative Research \& Evaluation Methods (4th ed.). SAGE Publications, Inc.

Pokhrel, S., \& Chhetri, R. (2021). A Literature Review on Impact of COVID-19 Pandemic on Teaching and Learning. Higher Education for the Future. https://doi.org/10.1007/978981-16-5411-4_9

Ryan, R. \& Deci, E. (2020). Self-Determination Theory and the facilitation of intrinsic motivation, social development, and well-being. Retrieved from https://selfdeterminationtheory.org/SDT/documents/2000_RyanDeci_SDT.pdf

Schleicher, A. (2020). The Impact of Covid-19 on Education - Insights from Education at a Glance 2020 @ Oecd 2020. Retrieved from https://www.oecd.org/education/the-impactof-covid-19-on-education-insights-education-at-a-glance-2020.pdf

Simbulan, N. P. (2020). COVID-19 and its Impact on Higher Education in the Philippines. Retrieved from https://headfoundation.org/2020/06/04/covid-19-and-its-impact-onhigher-education-in-the-philippines/

Tria, J. Z. (2020). The COVID-19 Pandemic through the Lens of Education in the Philippines: The New Normal. International Journal of Pedagogical Development and Lifelong Learning, 1(1), ep2001. https://doi.org/10.30935/ijpdll/8311

UNESCO IESALC. (2020). Covid-19 and Higher Education: Today and Tomorrow Impact 
Analysis, Policy Responses and Recommendations. Retrieved from http://www.iesalc.unesco.org/en/wp-content/uploads/2020/04/COVID-19-EN090420-2.pdf

United Nations. (2020a). Policy Brief: Education during COVID-19 and beyond. New York City: United Nations._Retrieved from https://www.un.org/development/desa/dspd

Waldeck, J. H., Johnson, Z., \& LaBelle, S. (2020). Confidence, Clarity, and Concern: Developing an Effective Teaching Persona, The best of the 2020 Teaching Professor Conference. Retrieved from https://www.magnapubs.com/wpcontent/uploads/2021/02/Best-of-TPC-2020.pdf

Zahneis, M. \& Williams A. (2020). How has the Pandemic affected graduate students? Retrieved from https://www.chronicle.com/article/how-has-the-pandemic-affectedgraduate-students-this-study-has-answers 